\title{
Mobile Robot with an Anthropomorphic Walking Device: Design and Simulation
}

\begin{abstract}
M. Polishchuk
Associate ProfessorNational Technical University of Ukraine Department of Technical Cybernetics

Ukraine

M.Tkach

Associate ProfessorNational Technical University of Ukraine Department of Technical Cybernetics Ukraine
\end{abstract}

The article presents a fundamentally new design of an anthropomorphic walking device for a mobile robot. The novelty of the proposed design lies in the fact that each part of the leg of the robot is made in the form of four corrugated pneumatic chambers that are mounted on spherical hinges. This design allows the robot to move in an angular coordinate system, which is typical for humans. A mathematical model of an elastic walking device is proposed and analytical dependences are given for calculating the geometric and strength parameters. The results of mathematical modelling and recommendations for the design of anthropomorphic walking mechanisms are given. The engineering formulas and diagrams for calculating power loads described in the article allow you to create various modifications of walking robots that have the property of adapting to an arbitrary surface topology for moving a mobile robot. The stated research results allow us to expand the technological capabilities of mobile robots.

Keywords: industrial robots, walking mechanisms, climbing robots, anthropomorphic devices, robots' design.

\section{INTRODUCTION}

The main purpose of creating walking mechanisms for mobile robots is to increase the patency of the robot on the surface of motion. There are many designs of walking devices for mobile robots. The most famous are mechanical devices with an electric or hydraulic drive. As a rule, these devices have a separate engine for each element of the leg of the robot - hips, leg shin and foot. Walking mechanisms have a lower speed of movement than robots with wheel transmission. However, the advantages of walking robots are best manifested when the topology of the surface of motion is a priori unknown. Improving the design of walking robots is aimed at ensuring their stability when moving on an arbitrary surface. To point out at the effectiveness of the known designs of walking robots, it should be noted that the drives of each leg of the robot in these devices move in $2 \mathrm{D}$ space, that is, in the plane. At the same time, maximum versatility can be achieved by moving legs of the robot in the 3D space of an angular coordinate system, which is characteristic of man. It is also important that the walking mechanism is applicable for mobile robots of arbitrary orientation in the technological space, that is, for climbing robots. Therefore, the problem of creating anthropomorphic walking mechanisms is relevant.

\section{PREREQUISITES AND MEANS FOR SOLVING THE PROBLEM.}

Received: August 2019, Accepted: October 2019

Correspondence to: M. Polischuk,

National University of Ukraine, Department of

Technical Cybernetics, Ukraine

E-mail: polishchuk.kpi@bk.ru

doi:10.5937/fmet2001013P

(C) Faculty of Mechanical Engineering, Belgrade. All rights reserved
Currently, in the field of robotics, quite effective anthropomorphic walking devices have been created for mobile robots, including robots of arbitrary orientation in the technological space. In studies [1], a kinematic scheme of a robot that has six legs is proposed. Each leg has two joints. The knee joint has one degree of freedom. Despite the fact that the hip joint has two degrees of freedom, this property is not enough for robots of arbitrary orientation in the technological space. Also in article [2], an adaptive control scheme of robotic systems is presented that capture and manipulates unknown objects. These works are of interest to improve the automatic control of the process of capturing objects, the shape and position of which are a priori unknown. The technical solutions of the walking legs of robots [3] and [4] contain vacuum gripping devices for holding robots on the surface of arbitrary orientation. However, the design of these robots' legs also has one degree of freedom, which limits their technological capabilities.

The original design of the walking robot is presented in studies [5]. This robot has the ability to move through the trees. Legs of the robot are made in the form of mechanical grips. Its body is a flexible console that can bend depending on the shape and size of the tree trunk. However, the presence of a flexible console in the form of springs leads to the accumulation of residual stresses. This property reduces the resource of a mobile robot industrial operation. The walking robot [6] is made in the form of levers and is connected by hinges with autonomous drives. The resource of such robot is larger and it can perform power technological operations. For example, on the surface of the aircraft fuselage during its manufacture. However, these robots, despite their effectiveness, can move only in a cylindrical coordinate 
system. At the same time, it is acceptable to have a robot foot design that allows us to work in other coordinate systems. For instance, in a spherical or rectangular coordinate system of Descartes. In this paper [7], a new method of the control and how a twolegged robot does walk were proposed. This method involves and allows monitoring the gravity center position of the robot. This allows ensuring the stability of its spatial position. However, in this paper there are no proposals for the design of the feet of the robot itself.

Unlike previous models, the walking robot RiSE of Boston Dynamics [8] has the ability to move not only in a cylindrical coordinate system, but also in a rectangular coordinate system. This property extends the technological capabilities of the robot. Robot can move along the wall of a high-rise building. However, the robot has six legs, and each leg of the robot has two electric drives. The presence of a large number of actuators complicates the design of the robot and control system. Anthropomorphic constructions [9] are as close as possible to the structures of animals and humans. The walking devices of these robots are made in the form of kinematic mechanisms with electric drives in articulated joints, each of which makes movement in 2D space, and taken together the anthropomorphic device has the ability to move in $3 \mathrm{D}$ space.

As noted in studies [10], if necessary, act autonomously and with an unknown state of the supporting surface, the robot must have a design with a greater degree of limb mobility. This leads to the need to build a complex control system. Therefore, information robots are operating in extreme conditions, with unknown terrain and should use complexion-board computing systems. The tasks of the control system are to control a large number of degrees of freedom, providing the required kinematic and dynamic parameters of walking machines. The ambiguity of the environment limits the use of rigid limb control algorithms. This is confirmed by studies [11], in which it was observed that the evolution of the morphology of robots might involve a gradual complication of manipulation devices at the initial stages of tuning, as well as an increase in the number of degrees of freedom and expansion of the ranges of sensors and executive mechanisms. For the creation of anthropomorphic gripping devices, the paper [12] is interesting, in which a pneumatic manual system from the subsystems of control and teleoperation is proposed. These systems allow for muscle modeling and can be used as didactic tools. Also, the effective use of teleoperations for controlling manipulators was proposed in [13]. The proposed technical solutions are ideally suited for training and management, but cannot be applied directly in the industry to perform technological operations.

A remarkable construction of a biomechanical arm with seven degrees of freedom and original drives was proposed in [14]. This technical solution illustrates the effectiveness of the use of anthropomorphic designs of robots to perform technological operations. However, in this work there are no solutions of walking devices for the movement of robots. In article [15], walking mechanisms of a miniature robot based on biological systems with two principles of movement with the help of legs are proposed. It is shown that using modern software engineering Bionics can be an effective tool. As the authors note, to obtain complete results, it is necessary to apply all the principles obtained in the analysis. However, in these studies there are no design solutions for the walking mechanism for an industrial robot. Based on the above research's analysis, it can be argued that the task of creating an anthropomorphic walking mechanism for mobile robots remains relevant.

\section{FORMULATION OF THE PROBLEM}

The purpose of this research is to expand the technological capabilities of the walking devices of mobile robots, namely ensuring the movement of each leg of the robot in the three-dimensional technological space of the Cartesian, spherical or angular coordinate system. It should be noted here that the angular coordinate system is a kind of spherical coordinate system and is distinguished by the absence of kinematic relations of translational motion and contains only links of angular motions characteristic of the human leg. In addition, for the engineering calculation of the parameters of the anthropomorphic walking mechanism of the robot, it is necessary to obtain the analytical dependences of the geometric and energy characteristics of such a device.

\section{SOLUTION OF THE PROBLEM UNDER CONSIDERATION.}

The aim of the research was achieved in three successive stages. At the first stage, a fundamentally new design of an anthropomorphic walking device was created. At the second stage, a mathematical model was developed for calculating the geometric and power parameters of this device. At the third stage, the analytical connections of the parameters of the walking device for a mobile robot were modelled.

\subsection{The design of the anthropomorphic device.}

For better understanding of the analytical model of the anthropomorphic walking device, we will first consider its construction (Figure 1). The robot consists of four legs. Each leg is fixed by means of hinges on the body of the robot. Like a human leg, each leg of a robot consists of three parts: the thigh, the shin of the leg and the foot. Feet of the robot have gripping devices that are necessary to hold the robot on the surface of its movement. A power unit, a module of pneumatic distributors of compressed air flows and an on-board computer are installed on the body of the robot. The novelty of the proposed design of the robot is confirmed by the publication [16]. Unlike the known designs of mobile walking robots, this model is as close as possible to the anthropomorphic walking mechanism peculiar to man. These properties of the construction considered below allow the robot to adapt to the topology of the surface on which it moves. Adaptation of the walking mechanism of the robot is necessary to overcome various obstacles in carrying out transport operations, as well as to expand the technological capabilities of the mobile robot. 


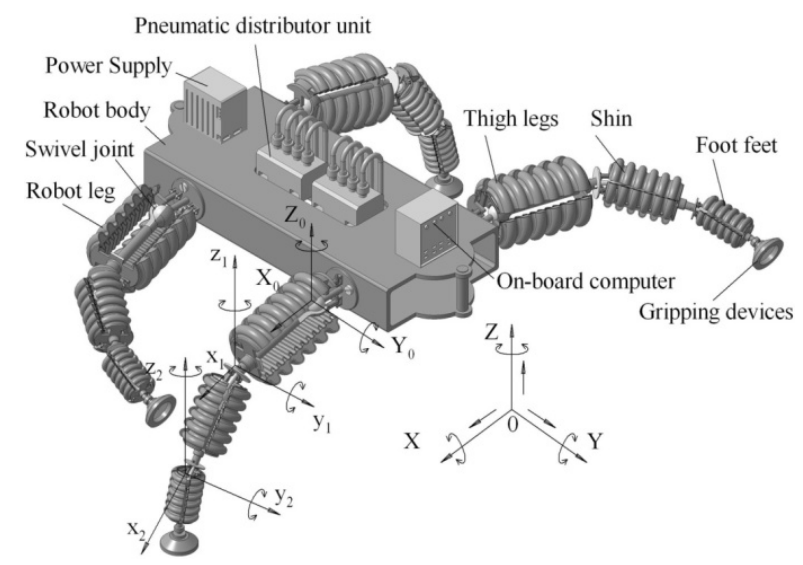

Figure 1. Mobile robot with anthropomorphic walking mechanism

The thighs of the legs, the shins and the feet, according to a given program, canmake turning movements in local coordinate systems, respectively: the thigh in the system $\mathrm{X}_{0} \mathrm{Y}_{0} \mathrm{Z}_{0}$; leg in $x_{1} y_{1} z_{1}$ and foot in the system $x_{2} y_{2} z_{2}$. As a result, the robot has six spans of mobility in the general system of coordinates $\mathrm{XYZ}$, and has: three translational movements and three turning movements. This number of degrees of mobility of the robot allows you to perform not only transport, but also any technological operations. The design of the robot leg is shown in more detail in Figure 2. Legs of the robot are mounted on the flanges of the robot body with the help of axles and pivoting levers. Each leg consists of the thigh of the leg, lower leg and foot. The design of each part of the leg of the robot is made in the form of corrugated pneumatic chambers mounted on rods with hinged joints. At the end of the leg there are gripping devices for coupling the robot with the displacement surface.

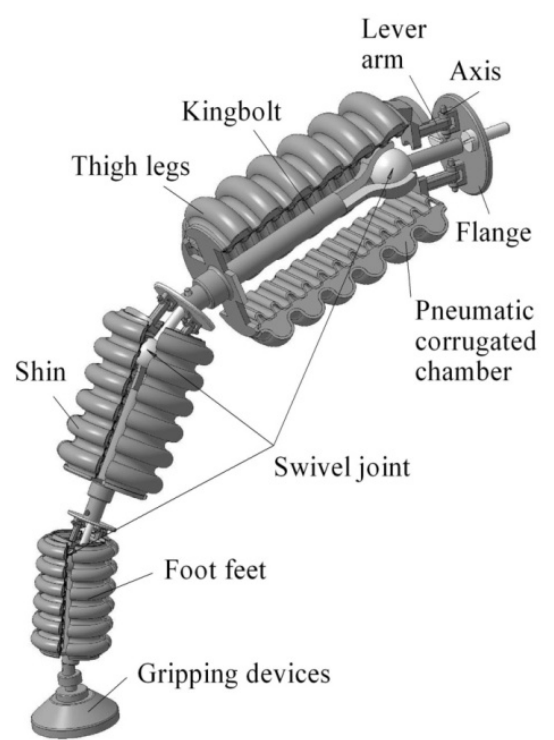

Figure 2. The design of the anthropomorphic leg of the robot

Executions of the specified gripping devices can have various designs, for example, they can be pneumatic or vacuum, mechanical or electromagnetic. Also, these gripping devices may use chemical or electrical adhesion properties. The choice of design of the gripping devices is determined by the topology and the physicomechanical properties of the surface for moving the mobile robot. In this article, these accomplishments are not considered, since, firstly, they are fairly well known, and secondly, the article is devoted to the new walking mechanism of a mobile robot itself. However, all of these types of grippers can be used for the walking mechanism described in this article.

At the ends of each part of the leg of the robot there are articulated joints. The first part is the leg thigh, fixed on the levers with the possibility of rotation around the axes mounted on the flange. Figure 3 shows the construction of a typical leg of a robot. The remaining parts of the leg: the shin and foot have the same design and differ only in smaller sizes. As stated above, each leg of the robot consists of four pneumatic corrugated chambers. These chambers are formed by large and small corrugated shells made of elastic material, for example, from high-strength polyvinyl chloride.

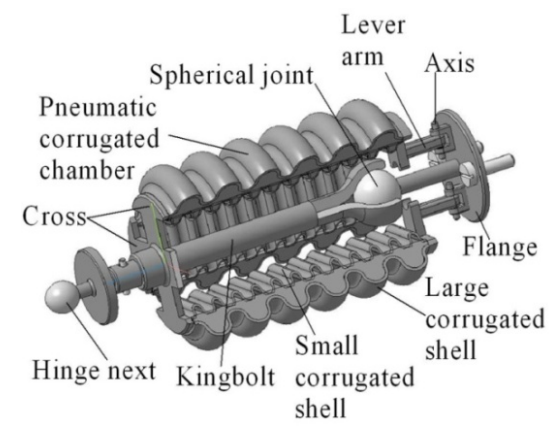

Figure 3. The design of the thigh of the leg of the robot in the form of corrugated chambers

The beginning of each chamber is fixed on the levers with the possibility of rotation around the axes of the flange. The ends of the cameras are fixed on the cross, which is mounted on an axis with the possibility of sliding. At the beginning and at the end of each part of the leg of the robot there are joints that allow the hip, lower leg and foot to rotate at an angle relative to each other. The pneumatic control circuit of the robot leg corrugated chambers is shown in Figure 4. A pneumatic compressor creates a stream of compressed air, which, according to a predetermined control algorithm, is distributed by automatic pneumatic valves to the corrugated chambers. Pressure regulators set the pressure of the compressed air in the chambers. Throttles with non-return valves regulate the rate of entry of compressed air into the chambers.

In the initial position, as shown in Figure 4, with equal pressures $p_{1}=p_{2}=p_{3}=p_{4}$, all four chambers occupy a straight position along the $\mathrm{Y}$ axis. But depending on the pressure difference $p_{1}$ and $p_{2}$ in the respective corrugated chambers. The leg part of the robot bends $\pm \alpha$ around the $\mathrm{X}$ axis. Under the condition of pressure differences $p_{2}$ and $p_{3}$, the chambers bend at $\pm \beta$ around the $Z$ axis. These corner bends of the corrugated pneumatic chambers are accompanied by translational $\pm \Delta y$ along the $Y$ axis in the XZY coordinate system. Corner bends of corrugated chambers occur due to the difference of the areas of large and small corrugated shell of each chamber. According to the specified algorithm, all parts of the leg 
of the robot work: thigh, shin and foot. As can be seen from Figure 5, the implementation of the indicated pressure combinations in the corrugated shells of the chambers allows orientation of the robot legs both in Cartesian XYZ and in the angular coordinate system $R, \beta, \gamma$ (where: $R$ is the radius of the sphere; $\beta, \gamma$ respectively, the angles of the legs). The angle $\alpha$ defines the service area of the anthropomorphic stepper device in an angular coordinate system.

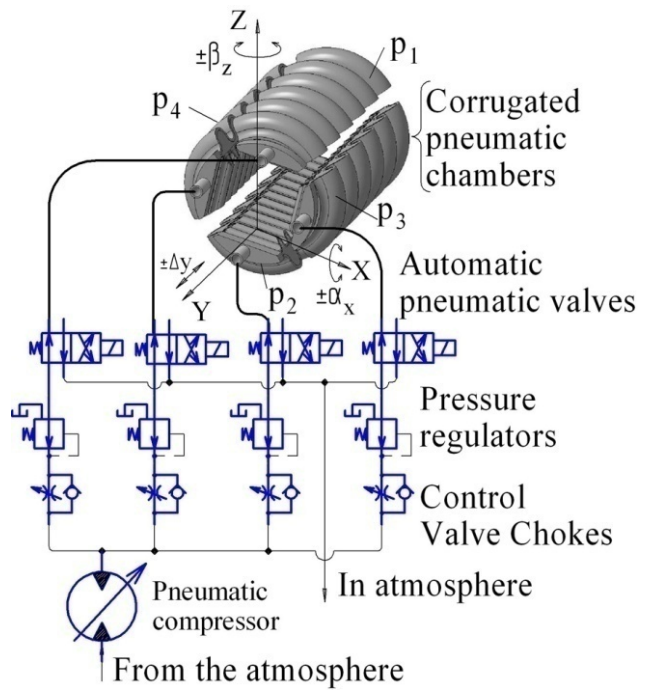

Figure 4. Pneumatic control circuit for corrugated chambers

The beginning of each chamber is fixed on the levers with the possibility of rotation around the axes of the flange. The ends of the cameras are fixed on the cross, which is mounted on an axis with the possibility of sliding. At the beginning and at the end of each part of the leg of the robot there are joints that allow the hip, lower leg and foot to rotate at an angle relative to each other. The pneumatic control circuit of the robot leg corrugated chambers is shown in Figure 4. A pneumatic compressor creates a stream of compressed air, which, according to a predetermined control algorithm, is distributed by automatic pneumatic valves to the corrugated chambers. Pressure regulators set the pressure of the compressed air in the chambers. Throttles with nonreturn valves regulate the rate of entry of compressed air into the chambers.

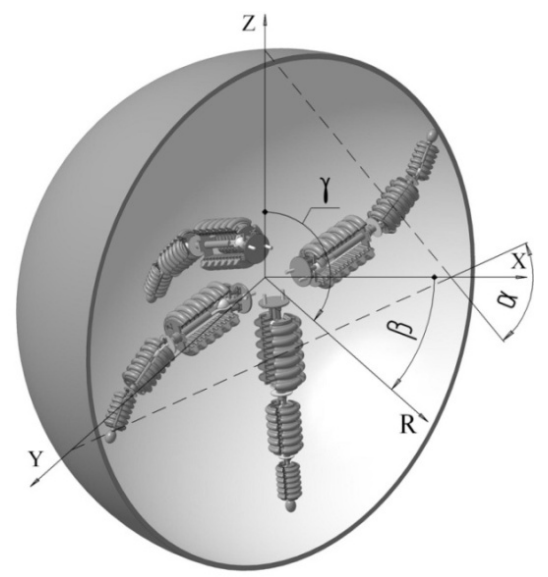

Figure 5. Variants of the position of the anthropomorphic legs of the robot in the angular coordinate system

\subsection{Mathematical model for calculating device para- meters}

The main element of the anthropomorphic device of the robot's legs is corrugated pneumatic chambers operating under pressure. The chambers of all parts of the leg of the robot: hips, legs and feet, are identical and differ only in their size, which decreases from hip to feet. Figure 6 shows the design diagram of the main structural element of the pneumatic chamber, namely the scheme of the corrugated shell that forms the chamber.

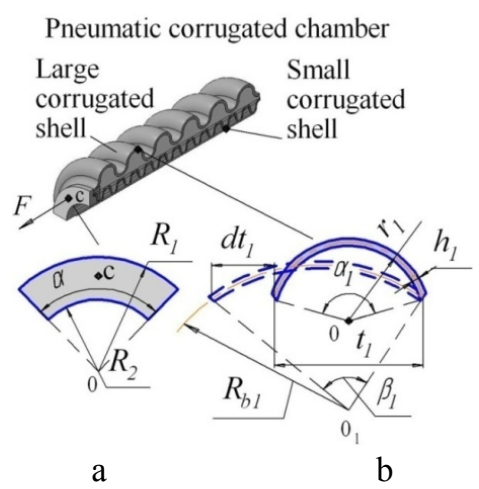

Figure 6. Design scheme of the corrugated shell a scheme stub; b - shell scheme

Pneumatic corrugated chamber is under pressure " $p$ " of compressed air. This pressure causes the action of the force $\mathrm{F}$ at the point "c" - the centre of mass of the end cap of the chamber. From Figure 6 (a)can be seen that the area "A" of the end cap is the area of the circular sector with radius $R_{1}$ with central angle $\alpha$ and radius $R_{2}$ :

$$
A=\frac{1}{2} \alpha\left(R_{1}^{2}-R_{2}^{2}\right)
$$

According to the scheme, the distance from the centre " 0 " to the centre of weight of the end cap "c":

$$
O C=\frac{4}{3} \frac{\sin (\alpha / 2)}{\alpha} \frac{R_{1}^{3}-R_{2}^{3}}{R_{1}^{2}-R_{2}^{2}}
$$

Due to the pneumatic pressure $p$, acts on the end cover of the chamber the force $\mathrm{F}$

$$
F=p A=\frac{1}{2} p \alpha\left(R_{1}^{2}-R_{2}^{2}\right)
$$

This force is distributed into two components $N_{1}$ and $N_{2}$, which stretch the large and small corrugated chambers. The values of these forces can be determined from the equilibrium equations:

$$
\begin{aligned}
& N_{1}+N_{2}=F \\
& F O C-N_{1} R_{1}-N_{2} R_{2}=0
\end{aligned}
$$

From these equations, we obtain the values of the forces $N_{1}$ and $N_{2}$ :

$$
\begin{aligned}
& N_{1}=\frac{1}{2} p \alpha\left(O C-R_{2}\right)\left(R_{1}+R_{2}\right) ; \\
& N_{2}=F \frac{R_{1}-O C}{R_{1}-R_{2}}=\frac{1}{2} p \alpha\left(R_{1}-O C\right)\left(R_{1}+R_{2}\right) .
\end{aligned}
$$

We define the relationship between the forces of $N_{1}$, $N_{2}$ and the elongation of the corrugated pneumatic cha- 
mbers. We assume that the elongation occurs only due to the stretching of the corrugated shells. Consider one element of a large corrugated shell of length $t_{1}$ with radius $r_{1}$ in Fig.6 (b). Under the action of force $N_{1}$, the element is extended by the value of $d t_{1}$, and the arc of a circle of radius $r_{1}$ goes into an arc of a circle of radius $\mathrm{R}_{\mathrm{bl}}$, while the arcs do not change their length. From the scheme of Fig.7 (b) it is easy to establish the following relations:

$$
\begin{aligned}
& \alpha_{1}=2 \arcsin \left(\frac{t_{1}}{2 r_{1}}\right) ; \quad R_{b 1}=\frac{r_{1} \alpha_{1}}{\beta_{1}} ; \\
& R_{b 1} \psi=r_{1} \varphi ; 0 \leq \varphi \leq \alpha_{1} ; 0 \leq \psi \leq \beta_{1} ; \\
& \Delta t_{1}=2 \frac{r_{1} \alpha_{1}}{\beta_{1}} \sin \left(\beta_{1} / 2\right)-t_{1},
\end{aligned}
$$

where: $\varphi, \psi$ are the current angles of the sectors (see Fig.7, b), which correspond to the elongation of the corrugated shell.

Similar relationships will also take place for the bottom small corrugated chamber:

$$
\begin{aligned}
& \alpha_{2}=2 \arcsin \left(\frac{t_{2}}{2 r_{2}}\right) ; \quad R_{b 1}=\frac{r_{2} \alpha_{2}}{\beta_{2}} ; \\
& R_{b 2} \psi=r_{2} \varphi ; 0 \leq \varphi \leq \alpha_{2} ; 0 \leq \psi \leq \beta_{2} ; \\
& \Delta t_{2}=2 \frac{r_{2} \alpha_{2}}{\beta_{2}} \sin \left(\beta_{2} / 2\right)-t_{2} .
\end{aligned}
$$

To control the position of legs of an anthropomorphic robot, it is necessary to know the analytical relationships between the power load and the amount of elongation of the corrugated pneumatic chambers. The change in length $\Delta \mathrm{t}_{1}$ (see Fig.6, b) of the upper large corrugated shell is determined using the well-known Mohr integral:

$$
\Delta t_{1}=\int_{0}^{\alpha_{1}} \frac{M_{p} \bar{M} r_{1} d \varphi}{E J_{1}}+\int_{0}^{\alpha_{1}} \frac{N_{p} \bar{N} r_{1} d \varphi}{E h_{1} R_{1} \alpha}
$$

where $h_{1}$ is the thickness of the material of a large corrugated shell; $J_{1}=\frac{\alpha R_{1} h_{1}^{3}}{12}-$ axial moment of inertia of the cross section of the shell; $E$ - Young's modulus of the material of the corrugated shell; $M_{\mathrm{p}}, N_{\mathrm{p}}$ - bending moment and longitudinal force from a given load. In this case:

$$
\begin{aligned}
& N_{p}=N_{1} \cos \left(\beta_{1} \varphi / \alpha_{1}-\beta_{1} / 2\right) \\
& M_{p}=N_{1} \frac{r_{1} \alpha_{1}}{\beta_{1}}\left(\cos \left(\beta_{1} \varphi / \alpha_{1}-\beta_{1} / 2\right)-\cos \left(\beta_{1} / 2\right),\right.
\end{aligned}
$$

also in the formula (8) - the bending moment and the longitudinal force from the applied unitary dimensionless force. In our case:

$$
\begin{aligned}
& \bar{N}=\cos \left(\beta_{1} \varphi / \alpha_{1}-\beta_{1} / 2\right) ; \\
& \bar{M}=\frac{r_{1} \alpha_{1}}{\beta_{1}}\left(\cos \left(\beta_{1} \varphi / \alpha_{1}-\beta_{1} / 2\right)-\cos \left(\beta_{1} / 2\right) .\right.
\end{aligned}
$$

Substituting the expression of the force factors (9) and (10) into formula (8), after integration, we obtain the change in the length $\Delta t_{1}$ of the large corrugated shell:
$\Delta t_{1}=\frac{r_{1} \alpha_{1} p k_{1}}{E}\left(\frac{1}{J_{1}}\left(\frac{\alpha_{1} r_{1}}{\beta_{1}}\right)^{2}\left(\frac{1}{2}+\cos ^{2}\left(\frac{\beta_{1}}{2}\right)-\frac{3 \sin \beta_{1}}{2 \beta_{1}}\right)+\right.$

$\left.+\frac{1}{2 h_{1} R_{1} \alpha}\left(1+\frac{\sin \beta_{1}}{\beta_{1}}\right)\right)$

where: $k_{1}=\frac{1}{2} \alpha\left(O C-R_{2}\right)\left(R_{1}+R_{2}\right)$.

Similarly, to the above procedure (8) - (11), which for brevity will not be repeated, we obtain the change in the length $\Delta t_{2}$ of the lower small corrugated shell:

$$
\Delta t_{2}=\frac{r_{2} \alpha_{2} p k_{2}}{E}\left(\begin{array}{l}
\frac{1}{J_{2}}\left(\frac{\alpha_{2} r_{2}}{\beta_{2}}\right)^{2}\left(\frac{1}{2}+\cos ^{2}\left(\frac{\beta_{2}}{2}\right)-\frac{3 \sin \beta_{2}}{2 \beta_{2}}\right)+ \\
+\frac{1}{2 h_{2} R_{2} \alpha}\left(1+\frac{\sin \beta_{2}}{\beta_{2}}\right)
\end{array}\right)
$$

where: $k_{2}=\frac{1}{2} \alpha\left(R_{1}-O C\right)\left(R_{1}+R_{2}\right)$. The names of all parameters (12) are the same as in formula (11) and differ in the "2" index, which corresponds to the parameters of small corrugated shell.

Solving the system of equations (6) and (11), as well as (7) and (12) numerically in the MATLAB environment, it is easy to find changes in the length of the large and small corrugated shells and the angles $\beta_{1}, \beta_{2}$ of their bending depending on the pressure of compressed air. The total elongation of the corrugated chambers of the robot leg can be found by formulas:

$$
d L_{1}=\frac{L}{t_{1}} \Delta t_{1} ; d L_{2}=\frac{L}{t_{2}} \Delta t_{2}
$$

where: $L$ is the length of the corrugated shell.

Now we can determine the bend angle $\varphi$ in degrees and the average radius $R_{\text {aver }}$ of curvature of the corrugated shell:

$$
\begin{aligned}
& \varphi=\frac{d L_{1}-d L_{2}}{R_{1}-R_{2}} \frac{180}{\pi} \\
& R_{\text {aver }}=\frac{\left(R_{1}-R_{2}\right)\left(L_{1}+L_{2}+d L_{1}+d L_{2}\right)}{2\left(d L_{1}-d L_{2}\right)} .
\end{aligned}
$$

As mentioned above, equations (11) and (12) are necessary to control the position of each part of the leg of the robot. However, engineering calculations of the strength of these parts of an anthropomorphic device require more formulas for calculating the maximum stresses $\sigma_{M 1}, \sigma_{M 2}, \sigma_{N 1}, \sigma_{N 2}$ arising in the material of small and large corrugated shells depending on the forces and moments (5), (9) and (10). We suggest calculating maximum stresses from bending moments and longitudinal forces using the formulas:

$$
\begin{aligned}
& \sigma_{M 1}=\frac{M_{1}^{\max }}{J_{1}} \frac{h_{1}}{2}=\frac{p k_{1} r_{1} \alpha_{1}}{\beta_{1}}\left(1-\cos \beta_{1}\right) ; \\
& \sigma_{M 2}=\frac{M_{2}^{\max }}{J_{2}} \frac{h_{2}}{2}=\frac{p k_{2} r_{2} \alpha_{2}}{\beta_{2}}\left(1-\cos \beta_{2}\right) ; \\
& \sigma_{N 1}=\frac{N_{1}^{\max }}{\alpha R_{1} h_{1}}=\frac{p k_{1}}{\alpha R_{1} h_{1}} ; \sigma_{N 2}=\frac{N_{2}^{\max }}{\alpha R_{2} h_{2}}=\frac{p k_{2}}{\alpha R_{2} h_{2}} .
\end{aligned}
$$




\section{SIMULATION RESULT}

According to the theoretical model above, the simulation of the corrugated shells of an anthropomorphic device was performed. For the material of the shells was selected polyvinyl chloride with a thickness of $h_{1}=0.003(\mathrm{~m})$ with the following characteristics: the density is $1.35 \cdot 10^{3} \ldots 1.43 \cdot 10^{3}\left(\mathrm{~kg} / \mathrm{m}^{3}\right)$; ultimate tensile strength $4 \cdot 10^{7} \ldots 7 \cdot 10^{7}(\mathrm{~Pa})$; flexural strength $8 \cdot 10^{7}$ $\ldots 12 \cdot 10^{7}(\mathrm{~Pa})$; Young's modulus $2.6 \cdot 10^{9} \ldots 4.0 \cdot 10^{9}(\mathrm{~Pa})$. The length of the corrugated chamber is $L=0.1(\mathrm{~m})$, the radius corrugation for a large chamber is $r_{1}=0.01(\mathrm{~m})$; for a small chamber, $r_{1}=0.08(\mathrm{~m})$. The range of pressure values in the chambers is $p=1 \cdot 10^{5} \ldots 10 \cdot 10^{5}(\mathrm{~Pa})$.

Figure 7 shows the simulation results of the process of elongation $d L$ of small and large corrugated shells. Figure 8 shows the change in angle $\beta$ of the bend of the phalanx of the fingers depending on the pressure in the corrugated pneumatic chamber. These charts recommended to be used as diagrams for controlling the position of parts of the legs of the robot: hips, legs and feet.

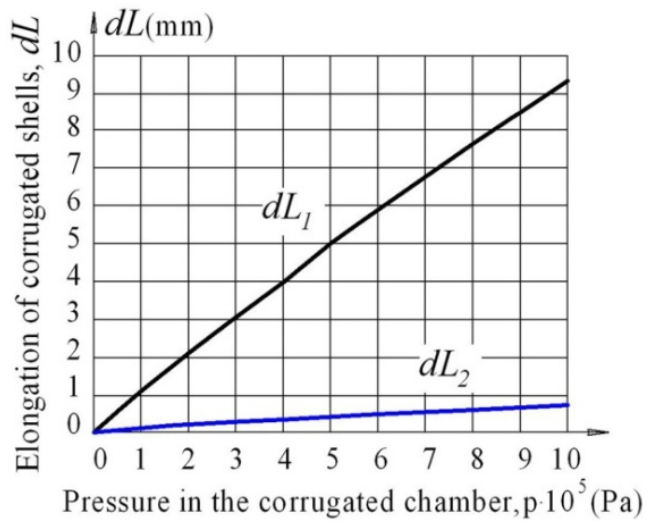

Figure 7. Elongation of large $d L_{1}$ and small $d L_{2}$ corrugated shells, depending on pressure $p$ in corrugated chambers.

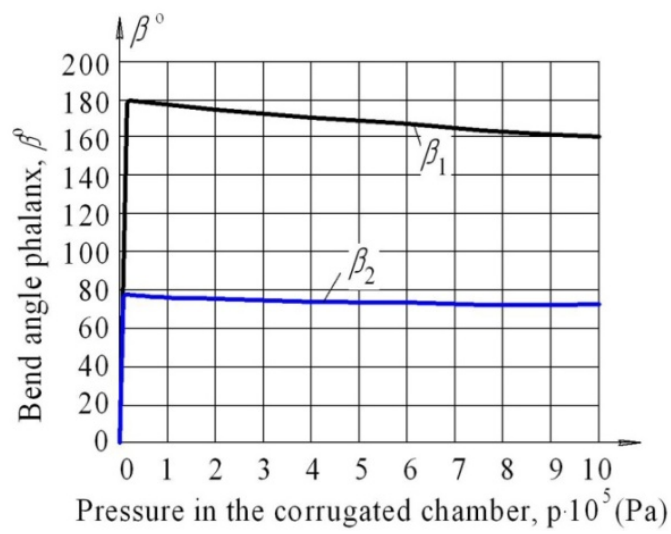

Figure 8. Changes in the bending angles ${ }_{1}$ and ${ }_{2}$ of the large and small corrugated shell.

For the design of leg parts of an anthropomorphic robot, it is recommended to use the graphs Figure 9 and Figure 10, which show the variation of the bending moments $M_{l}, M_{2}$ and the longitudinal forces $N_{l}, N_{2}$ depending on the pressure $\mathrm{p}$ in the corrugated sheaths of the thigh, shin and foot. If in the process of designing a device a different material is used, other than polyvinyl chloride and with other characteristics, then the values of $M_{l}, M_{2}, N_{l}$, and $N_{2}$ can be calculated using formulas (9) and (10).

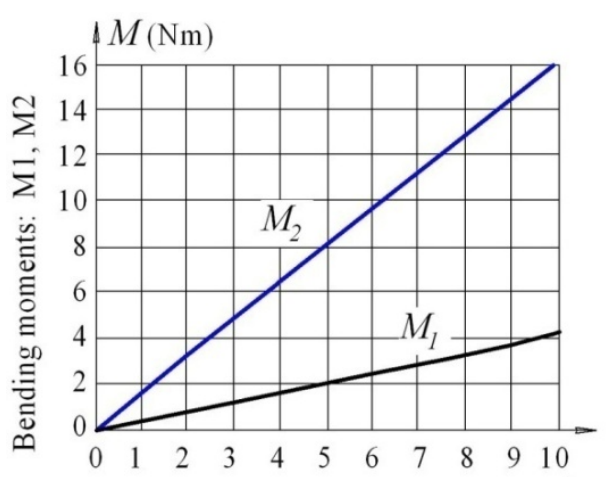

Pressure in the corrugated chamber, $\mathrm{p} \cdot 10^{5}(\mathrm{~Pa})$

Figure 9. Change of bending moments of large $M_{1}$ and small $M_{2}$ of corrugated shells depending on the pressure $p$ of the pneumatic chamber.

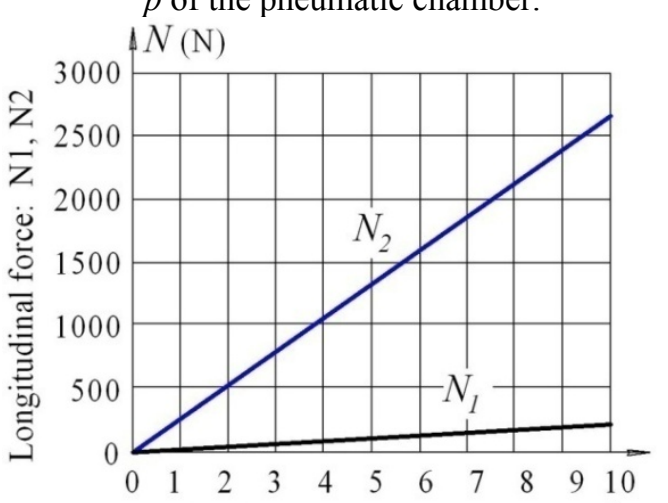

Pressure in the corrugated chamber, $\mathrm{p} \cdot 10^{5}(\mathrm{~Pa})$

Figure 10. Change in the longitudinal forces $N_{1}$ and $N_{2}$ in the large and small corrugated shells depending on the pressure $p$.

The simulation results of the stress variation $\sigma_{M 1}, \sigma_{M 2}$ due to the action of the bending moments $M_{1}, M_{2}$ in the corrugated shells and the stresses $\sigma_{N 1}, \sigma_{N 2}$ from the longitudinal forces $N_{l}, N_{2}$ are shown in Figure 11. These graphs should be used when calculating the strength of the thigh, lower leg and foot, taking into account the allowable stress for the material from which the corrugated shells are made.

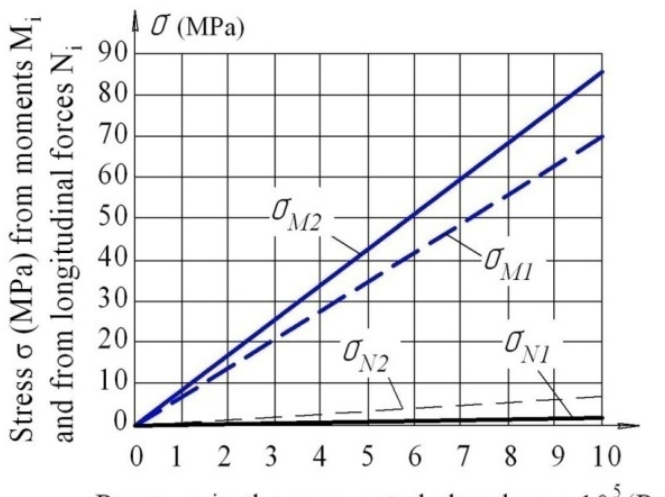

Pressure in the corrugated chamber, $\mathrm{p} \cdot 10^{5}(\mathrm{~Pa})$

Figure 11. The values of maximum stresses due to bending moment's $M_{1}, M_{2}$ and longitudinal forces $N_{1}, N_{2}$ in small and large corrugated shells

For this case, when polyvinyl chloride is used as a material for corrugated chambers, the values that were indicated in Figure 11 should not exceed the characteristics of the material, namely: tensile strength $4 \cdot 10^{7} \ldots 7 \cdot 10^{7}(\mathrm{~Pa})$ and flexural strength $8 \cdot 10^{7} \ldots 12$. 
$10^{7}(\mathrm{~Pa})$. For other elastic materials, restrictions should be imposed that will correspond to their limit values for allowable stresses. The maximum stresses from bending moments and longitudinal forces, which we propose to calculate using formulas (15), should not exceed the values of permissible stresses, which are characteristic of the material that will be used.

\section{RESULTS}

The new design of the anthropomorphic device of a mobile robot for moving over the surface, the shape and position of which is unknown a priori, presented in the article can be used to expand the technological capabilities of industrial robots for various purposes.

The proposed mathematical model of the elastic walking mechanism and analytical dependences for the calculation of geometric and power parameters are recommended for the design of anthropomorphic robots. The results of mathematical modelling are a theoretical justification of the industrial feasibility of using anthropomorphic devices of mobile robots.

In this article, for the first time are presented diagrams of changes in maximum stresses due to bending moments and longitudinal forces in corrugated pneumatic shells, which form the design of an anthropomorphic walking mechanism.

\section{DISCUSSION}

In contrast to the above designs of walking mobile robots, a fundamentally new design of the walking mechanism has been proposed. Due to the performance of the legs of the robot in the form of corrugated pneumatic chambers and the creation of various gas pressures in them, it is possible to arbitrarily orientate the legs of the robot in the technological space. Arbitrary orientation of robot's legs allows it to work in any coordinate system, for example, a rectangular Cartesian, cylindrical and angular coordinate system, which is peculiar to a human. These differences in the walking mechanism design significantly expand the technological capabilities of the mobile robot.

The proposed pneumatic actuator for the legs of the robot is optional. For heavy-duty robots, a hydraulic drive can be used and has a higher power density. Replacing a pneumatic drive with a hydraulic drive does not change the basic design of the device and its control system. It requires the use of more durable materials and hydraulic automation equipment.

\section{CONCLUSION}

The novelty of the proposed design from the known devices lies in the fact that each part of the leg of the robot: thigh, shin and foot, made in the form of four corrugated pneumatic chambers mounted on spherical hinges. This design allows the mobile robot to perform transport and technological operations in the angular coordinate system, which is typical for humans. This property provides the adaptation of the walking mechanism to any topology of the surface on which the mobile robot moves. The expansion of the technological capabilities of a mobile robot is achieved by independent movements of the anthropomorphic leg of the robot in 3D space.

Creating a theoretical model of the proposed anthropomorphic walking mechanism of a mobile robot is the first stage of the research. The plan for the next research envisages the manufacture of a prototype of this and the testing of its technological capabilities. The authors will be happy to share with the scientific community the results of experimental research in the next publication. However, the analytical formulas developed by the authors for calculating the power loads on the walking mechanism of the robot together with the simulation results allow you to create various modifications of an anthropomorphic robot. These new models will expand the technological capabilities of traditional industrial robots.

\section{REFERENCES}

[1] Ignatiev M.B., Vladimirov S.V., Sergeev M.B. et al. (2016). Walking robots - challenges and prospects. Innovation and expertise 2016; 2(17), pp. 131-132.

[2] Mehrabi E., Esfandiari K., Talebi A., Zareinejad M. (2015). Adaptive control of unknown robotic systems cooperating on handling of an unknown object. 3rd RSI International Conference on Robotics and Mechatronics (ICROM, October 2015. DOI: 10.1109/ICROM. 2015.7367843.

[3] Pack R.T., Iskarous M.Z. Climber robot. United States Patent: 5551525; 1996.

[4] Raju D.D, Jaju S.B. (2014). Developments in wall climbing robots: a review. International journal of engineering research and general science 2014; 2(3), pp. 36-37.

[5] Lam T., Xu Y. Tree (2012). Climbing Robot: Design, Kinematics and Motion Planning. New York: Springer Heidelberg; 2012.

[6] Hafenrichte J.L., Georgeson G.E. (2019). Walking robot. Patent US 10232897. Int. Cl. B25J 15/0019. Appl. No.: 14/885360; filed: 16.10.2015; Date of Patent 19.03.2019, pp. 7-9.

[7] Yamaguchi Masahiko (2019). Walking control method, walking control program and biped walking robot. Patent US 10183712. Int. Cl. B62D 57/032. Appl. No.: 15/585604; filed: 03.05.2017; Date of Patent 22.01.2019, pp. 1-3.

[8] Saundersa A., Goldmanb D.I, Fullb R.J., Buehlera M. (2015). The RiSE Climbing Robot: Body and Leg Design. Boston Dynamics, Unmanned Systems Technology VIII 2015; Vol. 6230, pp. 12-13.

[9] Boston Dynamics. Changing your idea of what robots can do. Received from https://www.boston dynamics.com; December 7, 2018.

[10]Fokin V. G., Shanygin S.V. (2015). Overview and development prospects of mobile walking robotic systems. Young scientist 2015; ISSN 2072-0297, 18 (98), pp. 207-215.

[11] Munasypov R. A, Moskvichev S. S. (2012). Method of synthesizing the movement strategy of an 
autonomous mobile robot based on evolutionary processes. Bulletin of Ufa State Aviation Technical University 2012; 3(48), pp. 56-62.

[12] A. J. U. Quevedo, Diaz E., Leon H. (2012). Human anthropomorphic gripper as an automation tool. Conference: Control, Automation and Systems (ICCAS), 12th International Conference. January 2012.

[13] Percy W. Lovon-Ramos, Roger Ripas-Mamani, Yessica Rosas-Cuevas (2016). Mixed Reality Applied to the Teleoperation of a 7-DOF Manipulator in Rescue Missions December 2016. Conference: Robotics Symposium and IV Brazilian Robotics Symposium (LARS/SBR), XIII Latin American.DOI: 10.1109/LARS-SBR.2016.57.

[14] M. Penčić, M. Čavić, B. Borovac. Development of the Low Backlash Planetary Gearbox for Humanoid Robots. FME Transactions. Volume 45, 1, 2017. pp. 122-123.

[15] Ilija Stevanović, Boško Rašuo. Development Of a Miniature Robot Based on Experience Inspired by Nature. FME Transactions. Volume 45, 1, 2017. pp. 189-191.

[16] Polishchuk M.M. Anthropomorphic brush of an industrial robot (2018). Ukrainian Institute of Intellectual Property, application for a patent No.: a201711458:Int.CI. B25J 15/08. filed: 23.11.2017; publ.: 26.03.2018. Bulletin No 6, pp. 6-8.

\section{МОБИЛНИ РОБОТ СА АНТРОПОМОРФНИМ \\ УРЕЪАЈЕМ ЗА ХОДАҢЕ: ДИЗАЈН И СИМУЛАЦИЈА}

\section{М. Полишћук, М. Ткаһ}

Чланак приказује потпуно нови дизајн антропоморфног уређаја за ходање код мобилног робота. Новину представља чињеница да је сваки део ноге робота израђен у облику четири ребрасте пнеуматске коморе постављене на сферне шарке. Овакав дизајн омогућава роботу да се креће у угаоном координатном систему, што је типично за људе.

Предложен је математички модел еластичног уређаја за ходање а дате су и аналитичке зависности за израчунавање геометријских и параметара чвстоће. Приказани су резултати математичког моделирања и дате су препоруке за дизајнирање антропоморфних механизама за ходање. Техничке формуле и дијаграми за израчунавање оптерећења снаге описани у раду омогућавају различите модификације робота који ходају а који имају својство адаптације на произвољну топологију површине по којој се крећу. Резултати наведеног истраживања омогућавају проширење технолошких могућности мобилних робота. 